\title{
Effect of habitat structural complexity on collembolan communities
}

\author{
$\operatorname{AUTHOR}(\mathrm{S})$ :
}

Saitoh, Seikoh; Fujii, Saori; Takeda, Hiroshi

CITATION:

Saitoh, Seikoh ...[et al]. Effect of habitat structural complexity on collembolan communities. Ecological Research 2013, 29(1): 81-90

\section{ISSUE DATE:}

2013-11-30

URL:

http://hdl.handle.net/2433/197377

\section{RIGHT:}

The final publication is available at Springer via http://dx.doi.org/10.1007/s11284-0131101-6; This is not the published version. Please cite only the published version.; この論文 は出版社版でありません。引用の際には出版社版をご確認ご利用ください。 
1 Title:

2 Effect of habitat structural complexity on collembolan communities

3

4

5

6 903-0213, Japan

11

Fax:

\section{Authors:}

Seikoh Saitoh ${ }^{\mathrm{a}, \mathrm{b}}$, Saori Fujii ${ }^{\mathrm{a}, \mathrm{c}}$, Hiroshi Takeda ${ }^{\mathrm{a}, \mathrm{d}}$

${ }^{a}$ Division of Environmental Science and Technology, Graduate School of Agriculture, Kyoto University, Kitashirakawaoiwake-cho, Kyoto 606-8502, Japan

bPresent address: Tropical Biosphere Research Center, Ryukyu University, Senbaru 1, Nishihara, Okinawa 'Present address: Department of Environment and Natural Sciences, Graduate School of Environment and Information Sciences, Yokohama National University, Yokohama 240-0067, Japan

dPresent address: Department of Environmental System, Faculty of Science and Technology, Doshisha University, 1-3 Tataramiyakodani, Kyotanabe 601-0394, Japan. 


\section{Abstract}

We investigated soil microarthropod communities in 2 physically dissimilar inorganic soil materials and in a mixture of these 2 materials to examine the effect of the structural complexity of a habitat on microarthropod abundance and communities, teasing it out from that of nutritional factors. Mesh boxes were filled with perlite (a highly porous material), similar size of granite gravels (no pores inside), or their mixture, and placed on a forest floor. The boxes were collected after 8 or 20 months, and the microarthropods were extracted and identified to the species level, with a focus on Collembola. We also evaluated fine-root biomass and the amount of organic matter in the boxes. It was found that the mixture of perlite and granite enhanced microarthropod abundance and root development. A partial redundancy analysis (pRDA) revealed that collembolan communities developed differently among the substrate materials. We also found that variation in the collembolan communities was related to fine-root development and the abundance of other microarthropods, implying that habitat structural complexity affects collembolan communities indirectly by affecting soil food webs.

Keywords: Collembola; community; habitat complexity; soil microarthropods; soil structure. 


\section{Introduction}

In soil, heterogeneity is the basis of biodiversity (Bardgett 2002). Communities of soil microarthropods, which are highly abundant in temperate forests (Petersen and Luxton 1982), are affected by litter types (Anderson 1975), litter decomposition stages (Hasegawa and Takeda 1995), and litter depth or strata in soil (Takeda 1978; Hågvar 1983; Ponge 2000). These factors interact to produce various biotic and abiotic environments in soil, resulting in diverse habitats for individual species.

Previous studies have highlighted the importance of habitat diversity on a small scale in soil (reviewed by Wardle 2002). Diverse combinations of litter materials provide a broad spectrum of substrates for decomposition, leading to the provision of diverse food resources for microarthropods. Similarly, in terms of physical habitat, the diversity in substrates translates to the presence of diverse habitable spaces for microarthropods. Further, because of its complexity, soil structure is thought to buffer species interactions, including competition and predation, and to contribute to the coexistence of different species (Anderson and Healey 1972; Wardle 1995). The positive correlation between the diversity of the habitat components of soil organic layers and microarthropod diversity supports these views (Anderson 1978).

In the aforementioned context, experiments have been conducted using multiple litter species as substrate materials to investigate whether habitat heterogeneity affects microarthropod communities in terms of species composition, abundance, and diversity. Studies on Collembola (Takeda 1987) and Oribatida (Hansen and Coleman 1998; Kaneko and Salamanca 1999; Hansen 2000) revealed that a mixture of litter types results in species compositions of microarthropod communities that are different from those observed when using a single litter type. Further, a mixture of litter types appears to have a positive effect on total soil microarthropod abundance (Kaneko and Salamanca 1999; Hansen 2000) and diversity (Hansen and Coleman 1998; Kaneko and Salamanca 1999; Hansen 2000). Hansen (2000) suggested that mixtures of litter types contribute to strengthening the soil physical structure, and thereby improve the properties of habitats, such as the amount and variety of habitable pore space, accumulation of fine organic particles, and development of plant fine roots and fungal hyphae, which would likely result in enhanced microarthropod communities.

In contrast, some studies on litter mixtures have failed to detect any clear effects of litter mixtures on 
microarthropod abundance (Blair et al. 1990; Wardle et al. 2006). Wardle et al. (2006) suggested that the nutritional quality of individual litter types, rather than the composition of the mixture, has a significant effect on soil biota. This indicates that trophic aspects of substrate materials used when studying such mixtures contribute to ambiguity in measurements of structural complexity. To elucidate the mechanisms by which the structural complexity of a habitat affects the development of soil ecosystems and microarthropod communities, it is necessary to exclude trophic factors of the substrate materials used in experiments analyzing such mixed substrates.

Accordingly, we decided to use mixtures of inorganic materials instead of litter. We utilized 2 inorganic materials with different physical traits: perlite, which has a porous structure, and granite, which is a non-porous material. When equal volumes of the 2 materials were mixed, the physical traits of the mixture, such as pore volume, surface area, and water-holding capacity, attained values that were intermediate of those of the 2 parent materials, while the system became more complex and spatially heterogeneous on a small scale. We compared the development of soil biota, especially collembolan communities, between mesocosms containing single materials (i.e., perlite or granite) and the mixture of these materials, to examine the effect of the structural complexity of a habitat.

We hypothesized that a mixture of inorganic materials would have positive effects on the abundance and species richness of microarthropods, as well as on biotic factors such as the accumulation of organic matter and elongation of plant roots in the developmental processes of ecosystems within mesocosms. An additional objective was to determine how such a mixture of inorganic materials affects individual collembolan species, and consequently, the collembolan community structure.

\section{Materials and methods}

The study was conducted in a temperate coniferous forest on a ridge in the Kamigamo Experimental Forest $\left(135.04^{\circ} \mathrm{E}, 35.46^{\circ} \mathrm{N} ; 220 \mathrm{~m}\right.$ ASL), Field Science Education and Research Center, Kyoto University, located in central Honshu Island, Japan. During the study period (from 2004 to 2007), the mean temperature was $14.8^{\circ} \mathrm{C}$ and the mean annual cumulative precipitation was $1485 \mathrm{~mm}$ (measured at the Kamigamo Experimental Forest office). 
The forest canopy was dominated by Japanese cypress (Chamaecyparis obtusa). The understory vegetation comprised Eurya japonica, Evodiopanax innovans, Camellia japonica, and Cleyera japonica. The soil humus type was moder, with an organic layer approximately 4-cm thick. Fine roots of Japanese cypress formed a root mat in the $\mathrm{A}_{0}$ layer.

Three treatments were prepared: perlite, granite, and a 1:1 (v/v) mixture of the 2. Perlite is highly porous and thus has a high water-holding capacity, unlike granite. Mean particle sizes were $4 \mathrm{~mm}$ and $5 \mathrm{~mm}$ for perlite and granite, respectively. Materials were rinsed with tap water before use.

Pore size distributions differed between treatments with respect to fine pore spaces smaller than $2.8 \mathrm{~mm}$ (Fig. 1): perlite has a large proportion of fine pore spaces, while granite is characterized by primarily macropore spaces. Their mixture exhibited intermediate characteristics. Pores larger than $44 \mu \mathrm{m}$ are accessible for soil microarthropods (Lavelle and Spain 2001). Pore size distributions were determined as follows. Material cores of $100 \mathrm{~cm}^{3}(n=3)$ were saturated with water, drained through a sandbed ( $\left.\mathrm{pF}=1.8\right)$, and subsequently exposed to a pressure plate (31 $\mathrm{kPa}$ ) to determine the maximum water-holding capacity, field capacity, and lento-capillary point, respectively. These correspond to pore sizes (diameters) of $2.8 \mathrm{~mm}, 44 \mu \mathrm{m}$, and $8.8 \mu \mathrm{m}$, respectively. Subsequently, the materials were oven dried at $70^{\circ} \mathrm{C}$. From the data, percent volumes of pores with diameters of $>2.8 \mathrm{~mm}, 2.8 \mathrm{~mm}-44 \mu \mathrm{m}, 44-8.8 \mu \mathrm{m}$, and $<8.8 \mu \mathrm{m}$ were determined.

We arranged plastic mesh boxes (mesh size $5 \mathrm{~mm} ; 12 \mathrm{~cm}$ [length] $\times 12 \mathrm{~cm}$ [width] $\times 8 \mathrm{~cm}$ [depth]) on the forest floor after removing the organic layer from under the bottom of each box on August 31, 2005. We created 10 contiguous $20-\mathrm{m}^{2}$ subplots and arranged a set of 3 boxes (one for each treatment) in each subplot; thus, 30 boxes (10 for each treatment) were established. Each box was filled with $1 \mathrm{~L}$ of the selected materials, and the top of each box was covered with 1-mm mesh to prevent the entry of large litter.

We collected the boxes from half the total number of subplots after 8 months (on April 20, 2006) and the remaining boxes after 20 months (on April 26, 2007). Thus, no samples were obtained from the same subplot in 2006 or 2007. After carefully cutting out fine roots with a knife, the boxes were placed in plastic bags and transported to the laboratory for analysis. Each box was placed on a Tullgren funnel to extract soil microarthropods. Extraction was performed for 7 days at a temperature of $35^{\circ} \mathrm{C}$. Water content was determined by 
comparing the weights of each box before and after extraction. Fine roots were collected using forceps, oven dried at $40^{\circ} \mathrm{C}$ for 3 days, and weighed to $0.1 \mathrm{mg}$. Organic matter was collected with a 2-mm sieve; the carbon content (mg C box ${ }^{-1}$ ) was then measured using an NC analyzer (Sumigraph NC-900; Sumitomo Chemical Co., Osaka, Japan) after milling the collected organic matter.

Microarthropods were identified to the species level for Collembola and to the order or suborder levels for other taxa, using a microscope. Collembola were categorized into 36 taxa; Tomocerus punctatus and T. varius were grouped as Tomocerus spp. since it was difficult to distinguish their juveniles from each other. Overall, the group appeared to be dominated by $T$. varius.

\section{Statistical analyses}

We conducted a one-way ANOVA followed by a multiple comparison test with Welch's $t$-test and a Bonferroni correction to analyze the differences in the mean values of the abundance of microarthropods, fine-root biomass, accumulated organic matter, water content, and species richness of Collembola at each sampling date among the treatments. Counts of microarthropod individuals were log-transformed before the analysis. To calculate species richness, the number of species and standard errors were estimated by the first-order jackknife procedure (Smith and van Belle 1984), and the estimated values were used in the ANOVA and multiple comparison tests. To examine the effects of the mixture on these measured values, we tested observed and predicted values using a paired $t$-test. The observed value was that of the corresponding variable in the mixture treatment, and the predicted value was calculated as the mean of the 2 single-material treatments for each subplot (Blair et al. 1990; Kaneko and Salamanca 1999; Wardle et al. 2006). To examine the effect of the mixture on species richness, the expected number of species in the mixture treatment, based on measuring the number of observed individuals, was estimated from the combined communities of the 2 single-material treatments, using a rarefaction method for each subplot. Differences between the estimated values and the number of observed species in the mixture treatment were then examined using a Wilcoxon signed-rank test.

To determine the ordination of the collembolan communities, we conducted RDA with forward selection of the 
higher microarthropod taxa, accumulated organic matter, fine-root biomass, and water content. Further, a partial RDA (pRDA) was conducted, in which the effects of elapsed time and subplot were separated out. The significances of the RDA axes were then calculated using a permutation test. We excluded 7 species from this analysis because we identified fewer than 5 individuals for them or found them in only one soil sample, taking into account the recommendation made by Hasegawa (2006). Redundancy analysis and selection of the explanatory variables for the analysis were performed with the software packages "vegan” (Oksanen et al. 2010) and "packfor" (Dray 2009), respectively. The latter is based on a forward selection method described by ter Braak and Šmilauer (2002).

\section{Results}

Figure 2 displays the abundance of soil microarthropods, environmental factors, and species richness of Collembola in the experimental boxes after 8 and 20 months. The abundance of Gamasida and fine-root biomass differed among the treatments after 20 months but not after 8 months (Figs. 2c, f). Fewer Gamasida individuals appeared in perlite samples than in the other 2 samples after 20 months; no other microarthropods exhibited any differences among the treatments (Figs. 2a, b, d). Fine-root biomass was lowest in the granite samples (Fig. 2f). Water content differed among the treatments, reflecting the amount of perlite in each sample: throughout the study period, we consistently observed the highest water content in perlite and the lowest in granite (Fig. 2g). At the first sampling date, a greater amount of organic matter was detected in perlite samples than in granite samples (Fig. 2e). Collembolan species richness did not differ among treatments (Fig. 2h).

We detected a positive effect of the perlite-granite mixture on the abundance of Collembola $(P=0.0123)$ on the first sampling date (Figs. 2a, h), on the abundances of Gamasida $(P=0.0736)$ and Prostigmata $(P=0.0352)$ on the second sampling date (Figs. 2c, d), on the abundance of Oribatida on the first $(P=0.0414)$ and second $(P=$ 0.0772) sampling dates (Fig. 2b), and on fine-root biomass on the first $(P=0.0675)$ and second $(P=0.0605)$ sampling dates (Fig. 2f). The effect on water content was negative on the first $(P=0.0126)$ and second $(P=$ 0.0023) sampling dates (Fig. 2g).

The dominant collembolan species, which accounted for more than $1 \%$ of the total collected collembolan 
individuals on at least one sampling date, are listed in Table 1. Folsomia octoculata was less abundant in granite than in the other 2 treatments on the first sampling date, while Arrhopalites sp. was the least abundant in perlite. Onychiurus flavescens appeared more abundant in perlite than in granite on the first sampling date, while Entomobrya sp. was more abundant in perlite than in granite on the second sampling date. In contrast, Tomocerus spp. was more abundant in granite than in perlite. With regard to the abundances of individual species, we detected a positive effect of the perlite-granite mixture on Tomocerus spp. $(P=0.0007), F$. octoculata $(P=$ 0.0046), F. japonica $(P=0.0552)$, and Arrhopalites sp. $(P=0.0981)$ on the first sampling date and Sinella dubiosa $(P=0.0290)$ and $F$. japonica $(P=0.0166)$ on the second sampling date.

In RDA, the elapsed time, water content, abundance of oribatids, fine-root biomass, and some subplots were selected as the explanatory variables using forward selection. These factors explained $65.4 \%$ of the total variation among the sampled collembolan communities. The effects of elapsed time and subplot as conditional factors were separated out in pRDA. The constraining factors in pRDA, namely, the abundance of oribatids, fine-root biomass and water content, explained $15.3 \%$ of the variance.

Ordination of the collembolan communities based on RDA is shown in Figure 3a. Axes 1 and 2 explained $22.2 \%$ and $15.4 \%$ of the total variance, respectively. A permutation test indicated that RDA axes $1-5$ were significant $(P<0.05)$. The ordination revealed relatively large effects of elapsed time and subplot on the collembolan communities (Fig. 3a). Arrows representing Oribatida and fine-root biomass, as well as elapsed time, were oriented in the lower right quadrant of the coordinate plane. Reflecting elapsed time, the majority of the communities sampled after 20 months were plotted in the lower half of the plane, whereas those sampled after 8 months were plotted in the upper half. Likewise, most collembolan taxa were plotted in the lower half of the plane, indicating their colonization of the substrates over time. Subplot had a considerable effect on ordination, indicating the effect of forest floor heterogeneity on the collembolan communities. For example, the arrows for subplots d, f, and g coincided with those of the communities sampled from those subplots.

In pRDA (Fig. 3b), in which the effects of subplot and elapsed time were separated out, the collembolan communities were plotted into 3 groups according to the treatments. Axes 1 and 2 explained $16.4 \%$ and $12.7 \%$ of the residual variance, respectively. A permutation test indicated that RDA axes 1 and 2 were significant $(P<0.05)$. 


\section{Discussion}

Microarthropod communities developed in our field-incubated mesocosms containing 2 inorganic materials and their mixture. As hypothesized, we found a positive effect of the mixture on the abundance of microarthropods

(Fig. 2), similar to the results of previous studies using mixed litter (Kaneko and Salamanca 1999; Hansen 2000).

Enhancement was observed in the animal taxa on the first and/or second sampling dates (Figs. 2a, b, c, d). With

whereas no positive effect was detected on species richness (Fig. 2h).

Although we expected enhancement of the accumulation of organic matter and development of fine roots in the experimental boxes, only the latter was actually observed (Figs. 2e, f). This may have contributed to the observed positive effects on microarthropod abundances to some extent. These findings suggest that habitat structural complexity may have a positive effect on the abundance of soil microarthropods, partly via enhancement of the development of fine roots, which could increase the availability of trophic resources.

The responses of individual collembolan species to the composition of the substrate varied among species (Table 1), with linear and non-linear responses exhibited (Fig. 3).

Effect of habitat structural complexity on the abundance of microarthropods and abiotic/biotic factors in

\section{the mesocosms}

In our system, inorganic materials served primarily as the physical framework of the habitat and received organic debris and fine roots from the surrounding organic layer, which likely served as energy sources in the experimental system. The fact that inorganic materials neither supplied any nutrients nor decomposed in the study period is important in interpreting the results of this study, compared with previous studies using mixtures of organic litter species. Those studies have suggested that mixing litters with dissimilar chemical traits improves food resource availability by stimulating microflora (Salamanca et al. 1998; Kaneko and Salamanca 1999), but this effect was absent in the present study. It has been also suggested that the slow decomposition of mixed litter makes these substrates superior at maintaining the physical structure and available pore space when compared to 
substrates based on single litter species, leading to a relatively higher capacity to entrain small organic particles (Hansen and Coleman 1998; Hansen 2000). Unlike previous studies, none of the examined material decomposed in the present study. This may explain why enhancement of the accumulation of organic matter was not observed.

We detected an enhancement of plant fine root growth. Interestingly, the amount of fine roots was equivalent between perlite and mixture samples on the second sampling date. Fine roots may have responded to merely the presence of fine pore spaces in perlite, which are important for root elongation (Pagliai and De Nobili 1993). The significance of this response is discussed later. Fine roots may have affected microarthropods via their role in supplying energy in the ecosystem (Wiggins et al. 1979, Parmelee et al. 1993). Nonetheless, variation in fine roots did not fully explain the microarthropod abundances, since no higher taxon displayed similar patterns in response to changes in fine root biomass (Figs. 2a-d, f). The responses of individual collembolan species to fine roots appeared to be varied. This implies the presence of some other unevaluated factor(s) or mechanism(s), involved with mixing perlite and granite, affecting microarthropod abundances.

Water content was evidently different among the treatments (Fig. 2g). Water content has been recognized to be one of the most important factors regulating the abundance of soil microarthropods; this fact has been confirmed in field studies (reviewed by Hopkin 1997). This is because soil fauna are generally less tolerant to desiccation than those aboveground, and even live fauna move downward and thus away from the topsoil when they sense desiccation (Swift et al. 1979). Nonetheless, it is the humidity in the soil pore spaces, rather than the water content, that affects soil microarthropods (Vanier 1987). In spite of the variation in water content between treatments, the humidity in the pore spaces of any treatment in the present study was likely at saturating levels, since we observed water films even on the granite particle surfaces during sampling, notwithstanding the fact that the granite treatment exhibited the lowest mean water content. Thus, we concluded that water content was unlikely to have affected microarthropod abundance in terms of desiccation.

A correlation between the total number of microarthropods and the amount of pore spaces of a certain size has been reported in the field (Vreeken-Buijs et al. 1998; Nielsen et al. 2008) and laboratory (Larsen et al. 2004). The field studies reported a correlation between Collembola and the amount of pores $>90 \mu \mathrm{m}$ in size in mineral soil (Vreeken-Buijs et al. 1998) and between Oribatida and the amount of pores 60-300 $\mu \mathrm{m}$ in size in the soil organic 
layer (Nielsen et al. 2008). Larsen et al (2004) conducted a soil compaction experiment to reveal the importance 247 of the amount of pores $120-300 \mu \mathrm{m}$ in size in influencing the abundance of certain collembolan species. These 248 studies indicated that the availability of habitable pore spaces for microarthropods could limit their abundance. In 249 the current study, the pore size range corresponding to that in the previous studies was $44 \mu \mathrm{m}-2.8 \mathrm{~mm}$. The amount of this size of pore was positively correlated with the amount of perlite (i.e., perlite $>$ mixture $>$ granite, Fig. 1). Unlike in the previous studies, no higher animal taxon showed any correlation to these pores (Figs. 2a-d), although some individual collembolan species displayed the pattern perlite $>$ mixture $>$ granite in terms of abundance (Table 1). Since all the treatments had high porosities (>50\%), the amount of pores was unlikely to have limited microarthropod abundances. Another possible explanation is that a large proportion of the pore spaces of the size range $44 \mu \mathrm{m}-2.8 \mathrm{~mm}$ may have been internal and closed (or narrow-necked) in perlite particles, and therefore would have been unavailable for microarthropods.

Focusing on the patterns of species-level responses to treatments, individual collembolan species responded differently (Table 1). Four different patterns of responses to the substrate material composition gradient were observed. (1) The 2 most abundant taxa on the second sampling date (Tomocerus spp. and Entomobrya sp.) responded differently, albeit linearly, to the 2 different materials. Their abundances in the mixture treatment approximated that of the mean of the 2 single-material treatments. (2) The mixture treatment enhanced the abundances of some species: Tomocerus spp. on the first sampling date, Sinella dubiosa on the second sampling date, and Friesea japonica on both sampling dates. (3) Some species were abundant in one of the 2 single-material treatments and also abundant at an equivalent level in the mixture treatment: Folsomia octoculata was abundant in perlite and in the mixture on the first sampling date whereas Arrhopalites sp. was abundant in granite and in the mixture treatment on the same date. (4) Some species were not clearly affected by the treatments: all the species apart from the abovementioned ones maintained similar abundance levels among the treatments. No species responded concavely to the material composition gradient. These response patterns are very similar to those reported by Takeda (1987), whose experiments involved mixtures with different ratios of pine-needle litter (Pinus densiflora) and broad-leaved litter (Alnus pendula). That study revealed that some collembolan species responded 
species richness values were similar among all treatments.

We hypothesize that the third pattern of response described above may represent a putative mechanism to explain how a mixture of materials generates a positive effect on the abundance of an organism. Assuming that a material is necessary for, or is preferred by, an organism but that its quantity is not limiting, such a response will be non-linear to the gradient of the mixture and reveal a positive effect of the mixture. Indeed, certain biotic components in the boxes were probably correlated with the presence, rather than amount, of perlite or granite. In other words, it appears that the fine-root biomass on the second sampling date responded positively and equally to the treatments that included perlite (perlite and mixture, Fig. 2f), while Oribatida responded positively and equally to the treatments that included granite (granite and mixture, Fig. 2b). Although fine roots responded specifically to the fine pore spaces contributed by perlite, as discussed earlier, it is unclear why Oribatida responded specifically to the treatments that included granite. Some collembolan species also responded in this manner: F. octoculata showed equivalent abundances between the perlite and mixture treatments but lower abundance in granite on the first sampling date, while Arrhopalites sp. did similarly but to the treatments that included granite on the same date (Table 1), although the actual factors to which they responded were not clear. More importantly, when 2 or more species display this type of response, but to different materials, their total abundance can form a single peak on the material composition gradient. This could be the reason for the positive effect on the total abundance of Collembola observed on the first sampling date (Fig. 2a). In other words, individual species responded non-linearly to different materials.

No clear effect of the mixing of inorganic materials on the number of collembolan species was detected (Fig. 2h). Studies that focused on oribatid communities (Hansen and Coleman 1998; Kaneko and Salamanca 1999; Hansen 2000) reported positive effects of substrate mixtures on species richness, whereas a study on collembolan communities did not (Takeda 1987), suggesting that this anomaly was potentially due to the differences in life histories between the 2 higher taxonomic groups. Oribatida species display distinct differences in food habits among species and low fecundity (Behan-Pletier and Hill 1983; Kaneko 1988; 1989), while Collembola species are omnivorous (reviewed by Hopkin 1997) and have relatively short generation times and iteroparity (Takeda 1987). This characteristic of Collembola may have been responsible for the equivalent numbers of 
species observed among the treatments, although community compositions indicated evident differences (Table

1).

\section{Effect of habitat structural complexity on collembolan communities in the experimental mesocosms}

Redundancy analysis revealed that the soil ecosystems and collembolan communities in the experimental boxes developed progressively with time (Fig. 3a). Subplots also affected the ordination, indicating that heterogeneity in the forest floor affected the collembolan communities. Because of these relatively large effects, the RDA did not reveal clear treatment effects. After a pRDA was conducted to eliminate the effects of elapsed time and subplot, the collembolan communities were clearly classified into 3 separate groups on the coordinate plane, based on treatment (Fig. 3b). This suggested the presence of relative differences in the compositions of the collembolan communities among the treatments. This also indicates that the communities that developed in the boxes with mixed substrates were not merely intermediate between those in the single-material boxes, since the 3 groups were graphically localized in different directions. As discussed above, this difference may have been generated by the varied responses, both linear and non-linear, of the species to the material gradients. This is in agreement with previous research conducted on litter. Kaneko and Salamanca (1999) and Hansen (2000) found that oribatid communities developed differently in substrates based on mixed or single litters.

The pRDA indicated that the water content, fine-root biomass, and abundance of oribatid mites was correlated with the variation among the collembolan communities. Water content was significantly different among treatments (Fig. 2g). In general, it is reasonable to consider that the water content affected the composition of the communities, since individual collembolan species may vary in their desiccation tolerance (Kærsgaard et al. 2004). However, the fact that the 2 most abundant collembolan taxa in the present study, Tomocerus spp. and Entomobrya sp., displayed contrasting responses on the second sampling date, i.e., the former was abundant in granite and the latter was abundant in perlite (Table 1) could not allow such a simplistic interpretation. Because both the genera can be considered to be relatively desiccation-tolerant (Takeda 1978), the variation among the treatments was not simply due to desiccation. In addition, as was discussed earlier, we believe that the mesocosms 
collembolan community. Water content was selected as a significant explanatory variable, likely because it was strongly correlated with the amount of perlite (Fig. 2g), representing the substrate material composition gradient among treatments to which some collembolan species linearly responded. Although pore spaces were not measured in every mesocosms and were not analyzed in the RDA, water content may have represented pore spaces because the 2 factors are closely correlated. As indicated by Larsen et al. (2004), some species may positively respond to the amount of pore spaces of a certain size, which would partially explain community differentiation.

The other factors selected by forward selection were fine-root biomass, and the abundance of oribatid mites. The pRDA axis 1 largely differentiated the communities in the treatments that included granite (i.e., $\mathrm{G}$ and $\mathrm{M}$ in Fig. 3b) from those in the perlite treatment $(\mathrm{P})$, while axis 2 differentiated the communities in the treatments that included perlite (i.e., P and M) from those in the granite treatment (G). Since these 2 axes were correlated with oribatid abundance and fine-root biomass, these factors may indicate some reasons for the observed responses of the communities. Given that fine roots largely represent a labile carbon source (due to root exudates) (Bais et al. 2006) while oribatid mites can represent dead plant material and fungi (Wallwork 1983), the observed differentiation of collembolan communities may have, to some extent, reflected fast and slow cycles in soil micro-food webs (Hunt et al. 1987; Moore et al. 2003). This hypothetical interpretation is not contradictory to a recent theory that the food habits of collembolan species vary, depending on the species, from bacteria to fungi (Berg et al. 2004; Kaneda and Kaneko 2004; Chahartaghi et al. 2005), although we did not determine the amounts of bacterial or fungal biomass. Interestingly, the pRDA axis 2 was largely correlated to the natural habitat. In particular, the abundances of F layer dwelling species (F. octoculata, O. yosiiana, and S. dubiosa) were correlated with fine root biomass. This was consistent with Fujii (2012) who suggested the role of fine roots as a food resource, leading to resource partitioning among collembolan species.

In this study, we analyzed 3 different types of field mesocosms, 2 single inorganic material treatments, and a mixture treatment, and discovered some positive effects on the abundance of arthropods and the development of different collembolan communities, although the underlying mechanisms responsible for the differentiation remain unresolved. Since potential trophic factors for soil organisms, such as the amounts of organic matter and 
fine roots, differed among the treatments, the direct effect of physical habitat could not be isolated from the direct and indirect effects of trophic factors. Although some studies have emphasized the potential importance of habitat for detritivorous microarthropods as a refuge from predators (Vreeken-Buijs et al. 1998; Hansen 2000; Nielsen et al. 2008), it was not practical to examine this approach in the present mesocosms. Therefore, future studies focusing on the structural habitat for soil microarthropods should control trophic factors by, for instance, forcing initial mesocosms to contain a certain amount of organic matter and preventing fine roots from invading them.

\section{Acknowledgments}

We thank the Field Science Education and Research Center, Kyoto University, Japan, for granting permission for conducting this study. We are obliged to Prof. K. Kitayama, Dr. M. Hasegawa, and Dr. A. Yamada for their useful comments on the manuscript; to Dr. K. Fujii for his cooperation in the measurements of pore size distribution of the materials; to Dr. M. Akutsu, Ms. K. Taneda, Ms. H. Mizuta, Mr. A. Shimizu, Mr. Y. Hagiwara, Mr. N. Endo, Dr. T. Haraguchi, and Ms. W. Saito for their kind cooperation; to the anonymous reviewers for their careful reading and constructive comments. S.F. was supported by the JSPS Research Fellowships for Young Scientists. Our study was partly supported by a Grant-in-Aid for the 21st Century COE Program for Innovative Food and Environmental Studies Pioneered by Entomomimetic Sciences, from the Ministry of Education, Culture, Sports, Science and Technology of Japan.

\section{References}

Anderson JM (1975) Succession, diversity and trophic relationships of some soil animals in decomposing leaf litter. J Anim Ecol 44: 475-495

Anderson JM (1978) Inter- and intra-habitat relationships between woodland Cryptostigmata species diversity and the diversity of soil and litter microhabitats. Oecologia 32: 341-348

Anderson JM, Healey IN (1972) Seasonal and interspecific variations in the major components of the gut contents of some woodland Collembola. J Anim Ecol 41: 359-368

Bais HP, Weir TL, Perry LG, Gilroy S, Vivanco JM (2006) The role of root exudates in rhizosphere interactions 
with plants and other organisms. Ann Rev Plant Biol 57: 233-266

Bardgett RD (2002) Causes and consequences of biological diversity in soil. Zoology 105: 367-374

Behan-Pelletier VM, Hill SB (1983) Feeding habits of sixteen species of Oribatei (Acari) from an acid peat bog, Glenamoy, Ireland. Rev Ecol Biol Sol 20: 221-267

Berg MP, Stoffer M, van den Heuvel HH (2004) Feeding guilds in Collembola based on digestive enzymes. Pedobiologia 48: 589-601

Blair JM, Parmelee RW, Beare MH (1990) Decay rates, nitrogen fluxes, and decomposer communities of singleand mixed-species foliar litter. Ecology 71: 1976-1985

Chahartaghi M, Langel R, Scheu S, Ruess L (2005) Feeding guilds in Collembola based on nitrogen stable isotope ratios. Soil Biol Biochem 37: 1718-1725

Dray S, Legendre P, Blanchet G (2009) packfor: Forward Selection with permutation (Canoco p.46). R package version 0.0-7/r58. http://R-Forge.R-project.org/projects/sedar/

Fujii S (2012) Effect of fine roots on the organization of collembolan community in a forest ecosystem. Doctoral thesis. Kyoto University, Kyoto. 92 pp

Hågvar S (1983) Collembola in Norwegian coniferous forest soils II: Vertical distribution. Pedobiologia 25: 383401

Hansen RA (2000) Effects of habitat complexity and composition on a diverse litter microarthropod assemblage. Ecology 81: 1120-1132

Hansen RA, Coleman DC (1998) Litter complexity and composition are determinants of the diversity and species composition of oribatid mites (Acari: Oribatida) in litterbags. Appl Soil Ecol 9: 17-23

Hasegawa M (2006) Application of ordination in community ecology of soil animals. Edaphologia 80: 35-64 (in Japanese with English summary)

Hasegawa M, Takeda H (1995) Changes in feeding attributes of four collembolan populations during the decomposition process of pine needles. Pedobiologia 39: 155-169

Hopkin SP (1997) Biology of the Springtails (Insecta: Collembola). Oxford University Press, Oxford. 330 pp

Hunt HW, Coleman DC, Ingham ER, Ingham RE, Elliott ET, Moore JC, Rose SL, Reid CPP, Morley CR (1987) 
The detrital food web in a shortgrass prairie. Biol Fertil Soils 3: 57-68

Kaneda S, Kaneko N (2004) The feeding preference of a collembolan (Folsomia candida Willem) on ectomycorrhiza (Pisolithus tinctorius (Pers.)) varies with mycelial growth condition and vitality. Appl Soil Ecol 27: $1-5$

Kaneko N (1988) Feeding habits and cheliceral size of oribatid mites in cool temperate forest soils in Japan. Rev Ecol Biol Sol 25: 353-363

Kaneko N (1989) Life histories of four oribatid mite species in a mull type soil in a cool temperate forest in Japan. Pedobiologia 33: 117-126

Kaneko N, Salamanca N (1999) Mixed leaf litter effects on decomposition rates and soil arthropod communities in an oak-pine forest stand in Japan. Ecol Res 14: 131-138

Kærsgaard CW, Holmstrup M, Malte H, Bayley M (2004) The importance of cuticular permeability, osmolyte production and body size for the desiccation resistance of nine species of Collembola. J Insect Physiol 50: 5-15

Larsen T, Schjonning P, Axelsen J (2004) The impact of soil compaction on euedaphic Collembola. Appl Soil Ecol 26: $273-281$

Lavelle P, Spain AV (2001) Soil Ecology. Kluwer Academic Publishers, Dordrecht. 654 pp

Moore JC, McCann K, Setälä H, De Ruiter PC (2003) Top-down is bottom-up: Does predation in the rhizosphere regulate aboveground dynamics? Ecology 84: 846-857

Nielsen UN, Osler GHR, van der Wal R, Campbell CD, Burslem DFRP (2008) Soil pore volume and the abundance of soil mites in two contrasting habitats. Soil Biol Biochem 40: 1538-1541

Oksanen J, Blanchet FG, Kindt R, Legendre P, O’Hara RB, Simpson GL, Solymos P, Henry M, Stevens H, Wagner H (2010) vegan: Community Ecology Package. R package version 1.17-2. URL http://CRAN.Rproject.org/package=vegan

Pagliai M, De Nobili M (1993) Relationships between soil porosity, root development and soil enzyme activity in cultivated soils. Geoderma 56: 243-256

Parmelee RW, Ehrenfeld JG, Tate RL (1993) Effects of pine roots on microorganisms, fauna, and nitrogen availability in two soil horizons of a coniferous forest spodosol. Biol Fertil Soils 15: 113-119 
Petersen H, Luxton M (1982) A comparative analysis of soil fauna populations and their role in decomposition processes. Oikos 39: 287-388

Ponge JF (2000) Vertical distribution of Collembola (Hexapoda) and their food resources in organic horizons of beech forests. Biol Fertil Soils 32: 508-522

Salamanca EF, Kaneko N, Katagiri S (1998) Effects of leaf litter mixtures on the decomposition of Quercus serrata and Pinus densiflora using field and laboratory microcosm methods. Ecol Eng 10: 53-73

Smith EP, van Belle G (1984) Nonparametric estimation of species richness. Biometrics 40: 119-129

Swift MJ, Heal OW, Anderson JM (1979) Decomposition in terrestrial ecosystems. Blackwell Scientific Publications, London. 384 pp

Takeda H (1978) Ecological studies of collembolan populations in a pine forest. II. Vertical distribution of Collembola. Pedobiologia 18: 22-30

Takeda H (1987) Dynamics and maintenance of collembolan community structure in a forest soil system. Res Popul Ecol 29: 291-346

ter Braak CJF, Šmilauer P (2002) CANOCO Reference Manual and CanoDraw for Windows User's Guide: Software for Canonical Community Ordination (version 4.5). Microcomputer Power, New York. 500 pp.

Vannier G (1987) The porosphere as an ecological medium emphasized in Professor Ghilarov's work on soil animal adaptations. Biol Fertil Soils 3: 39-44

Vreeken-Buijs MJ, Hassink J, Brussaard L (1998) Relationships of soil microarthropod biomass with organic matter and pore size distribution in soils under different land use. Soil Biol Biochem 30: 97-106

Wallwork JA (1983) Oribatids in forest ecosystems. Ann Rev Entomol 28: 109-130

Wardle DA (1995) Impacts of disturbance on detritus food webs in agro-ecosystems of contrasting tillage and weed management strategies. Adv Ecol Res 26: 105-185

Wardle DA (2002) Communities and ecosystems: linking the aboveground and belowground components. Princeton University Press, Princeton. 392 pp

Wardle DA, Yeates GW, Barker GM, Bonner KI (2006) The influence of plant litter diversity on decomposer abundance and diversity. Soil Biol Biochem 38: 1052-1062 
454 Wiggins EA, Curl EA, Harper JD (1979) Effects of soil fertility and cotton rhizosphere on populations of $455 \quad$ Collembola. Pedobiologia 19: 75-82

456 
458 Figure 1: Pore size distribution in the experimental boxes: Filled parts of columns denote solid matter. Each column represents the mean of 3 replicates. P, perlite; M, mixture; G, granite.

Figure 2: Abundance of soil microarthropods (a-d), environmental factors (e-g), and species richness of Collembola (h) in the experimental soil boxes after 8 and 20 months: White, gray, and black columns indicate the values for perlite, mixture, and granite treatments, respectively. Bars indicate 1 standard error $(n=5)$. The number of species and standard errors were estimated by the first-order jackknife procedure. Subscripts indicate significant differences in the mean values on the same sampling date $(P<0.05)$. Note that the multiple comparison test was conducted when the effect of treatment was revealed to be significant in a one-way analysis of variance (ANOVA). Asterisks indicate statistically significant differences in the observed and predicted

Figure 3: Ordination of collembolan communities that developed in perlite, granite, and their mixture: Ordination was based on (a) redundancy analysis (RDA) and (b) partial RDA (pRDA) in which the effects of elapsed time and subplot were separated. Codes for the communities (black) are as follows: the first letter (P, G, or M) indicates the treatment (perlite, granite, or mixture, respectively); the number in the middle (1 or 2 ) indicates the sampling date (after 8 or 20 months, respectively); and the third letter (a-j) indicates the subplot. For example, M2d indicates the collembolan community for treatment $M$ in subplot d, sampled 20 months after the experimental soil boxes were established. Arrows represent the factors (abundance of microarthropods, fine-root biomass, accumulated organic matter, water content, subplot, and elapsed time). The 15 dominant collembolan taxa (each accounting for $>1 \%$ of the total number of individuals on at least one sampling date) are shown in red. Abbreviations used for the collembolan taxa are as follows: Arpl, Arrhopalites sp.; Dsri, Desoria sp.3; Etmb, Entomobrya sp.; Flsm, Folsomia octoculata; Frsj, Friesea japonica; Istm, Isotoma carpenteri; Lpdc, Lepidocyrtus sp.; Lpgt, Lophognathella choreutes; Mglt, Megalothorax minimus; Ocpd, Oncopodura yosiiana; Onyf, Onychiurus flavescens; Smth, Sminthurinus sp.; Snld, Sinella dubiosa; Tmcr, Tomocerus spp.; Ttrc, 
485 Table 1: Abundances of dominant collembolan species in the experimental boxes after 8 and 20 months.

486 A total of 15 taxa (each accounting for $>1 \%$ of the total number of collembolan individuals on at least one sampling date) are shown. Values indicate the number of individuals per box. Parenthetical values indicate 1 standard error $(n=5)$. Superscripts indicate significant differences among the mean values of the treatments $(P$ $<0.05$ ). Note that the multiple comparison test was conducted when the effect of treatment was revealed to be 490 significant in a one-way analysis of variance (ANOVA). Data on the habitats of individual species in the soil 491 organic layer are from Takeda (1978): L, F, and H represent litter layer, fermented layer, and humus layer, 492 respectively. Hyphenated letters L-F and F-H indicate that the species inhabit(s) both layers. Asterisks indicate 493 statistically significant differences between the observed and predicted values: $+P<0.10$; ${ }^{*} P<0.05$; ${ }^{* *} P<$ $0.01 ; * * * P<0.001 ;$ ns, not significant. 


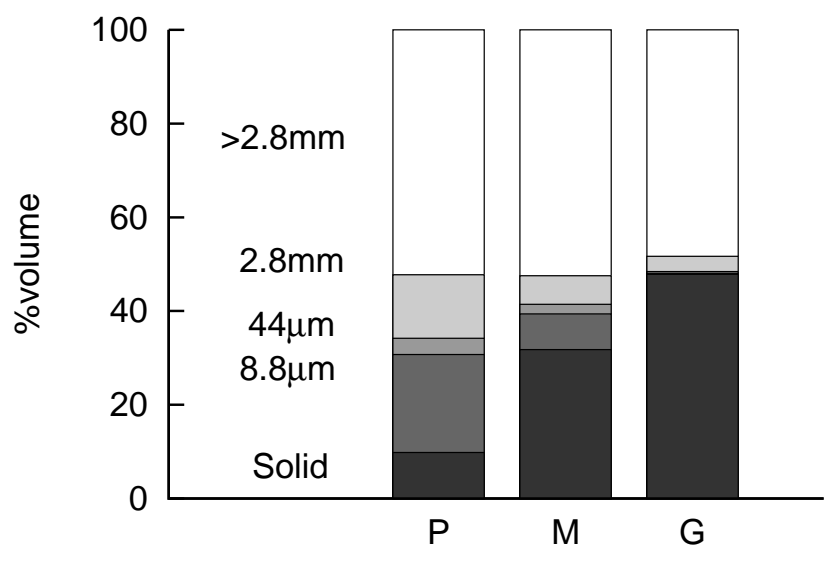

Treatment

Figure 1: Pore size distribution in the experimental boxes: Filled parts of columns denote solid matter. Each column represents the mean of 3 replicates. P, perlite; M, mixture; G, granite. 
(a) Abundance of Collembola

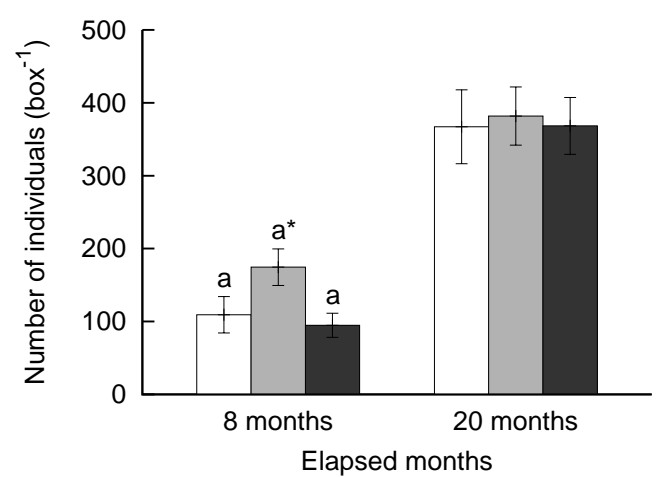

(c) Abundance of Gamasida

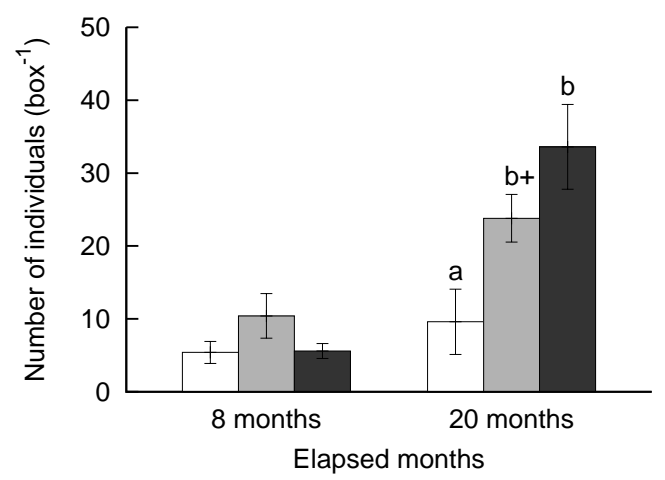

(e) Organic matter

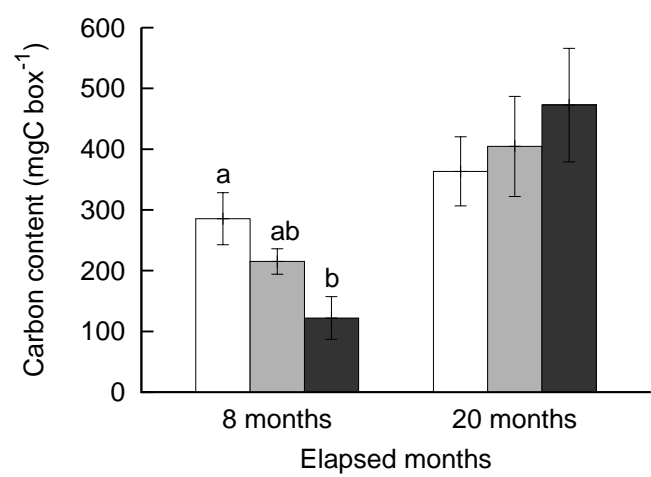

(g) Water content

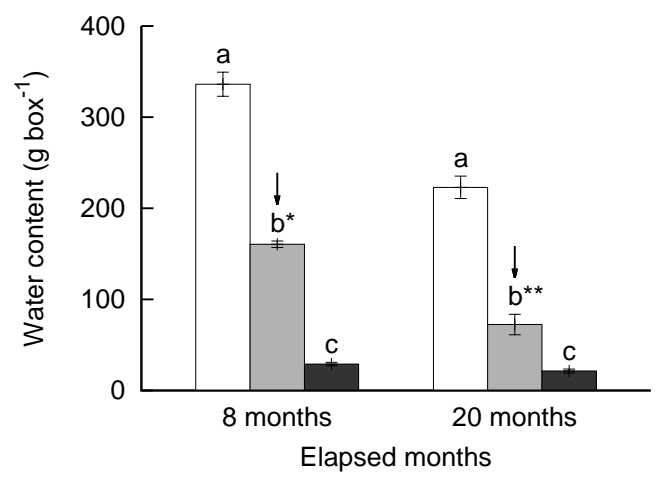

(b) Abundance of Oribatida

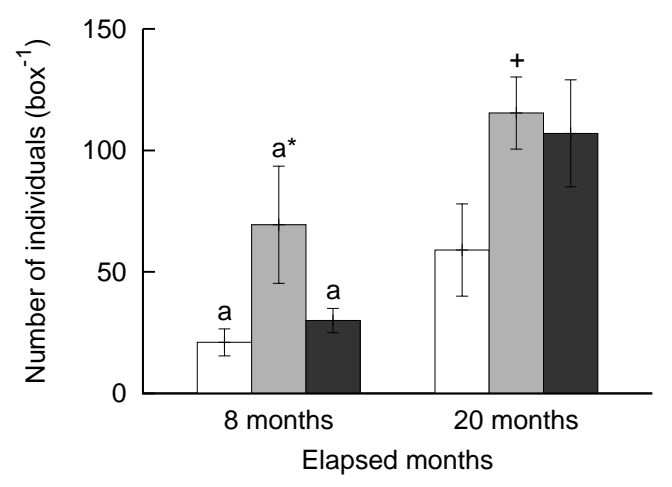

(d) Abundance of Prostigmata

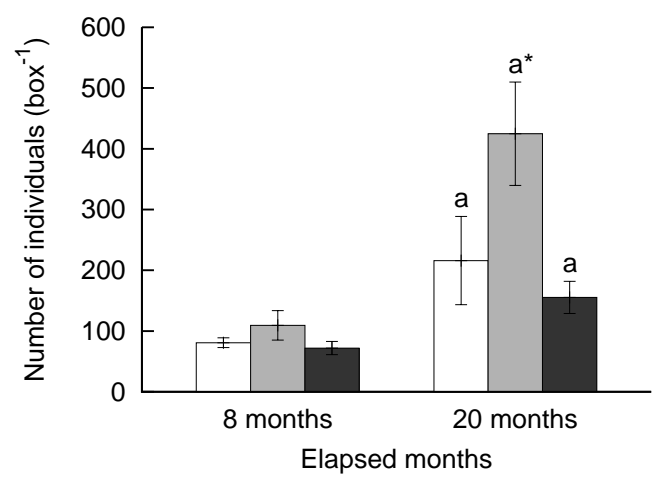

(f) Fine-root biomass

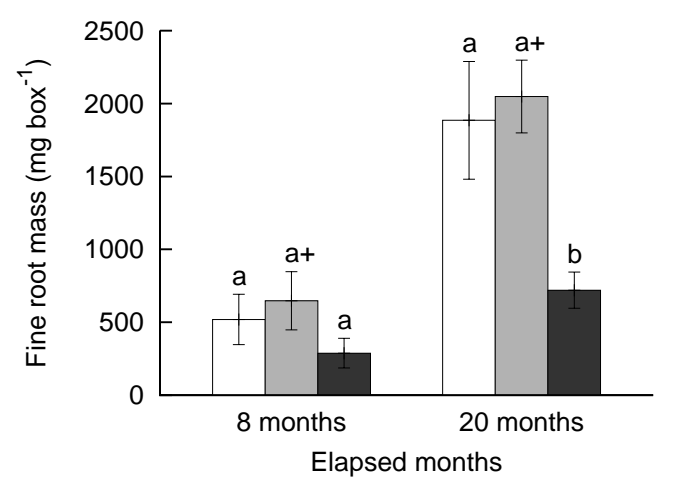

(h) Species richness of Collembola

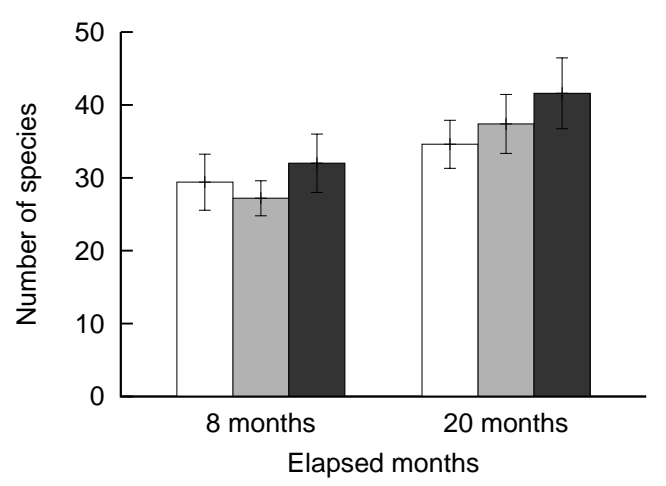

Figure 2: Abundance of soil microarthropods (a-d), environmental factors (e-g), and species richness of Collembola (h) in the experimental soil boxes after 8 and 20 months: White, gray, and black columns indicate the values for perlite, mixture, and granite treatments, respectively. Bars indicate 1 standard error $(n=5)$. The number of species and standard errors were estimated by the first-order jackknife procedure. Subscripts indicate significant differences in the mean values on the same sampling date $(P<0.05)$. Note that the multiple comparison test was conducted when the effect of treatment was revealed to be significant in a one-way analysis of variance (ANOVA). Asterisks indicate statistically significant differences in the observed and predicted values for the mixture treatment: $+P<0.10 ; * P<0.05$; $* * P<0.01$. Arrows indicate a negative effect 
(a) RDA

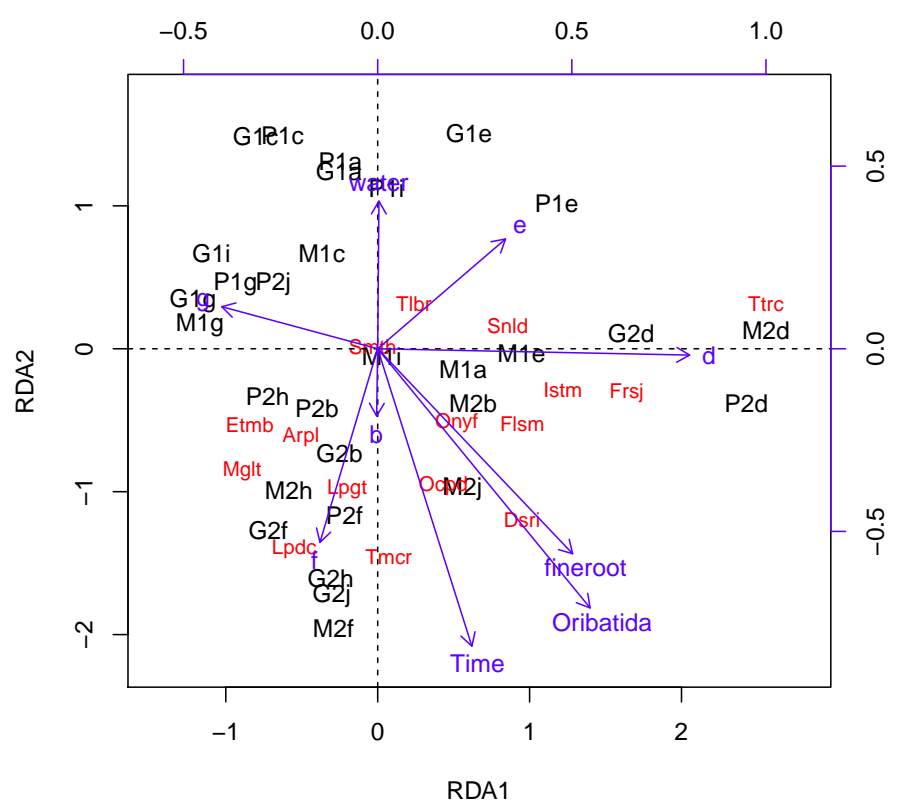

(b) pRDA

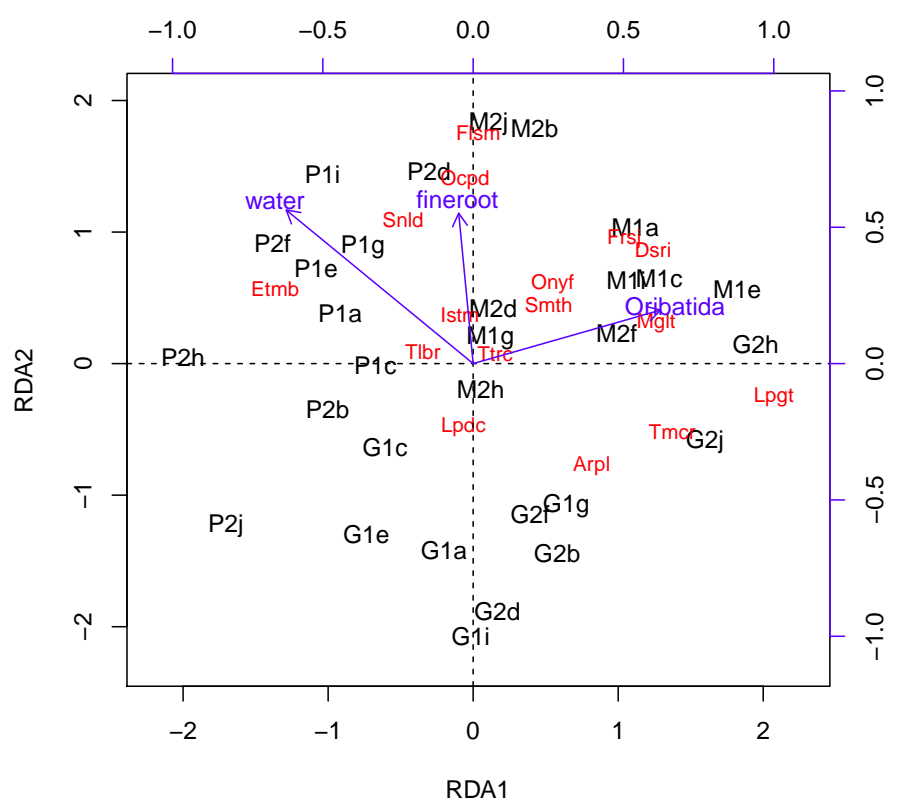

Figure 3: Ordination of collembolan communities that developed in perlite, granite, and their mixture: Ordination was based on (a) redundancy analysis (RDA) and (b) partial RDA (pRDA) in which the effects of elapsed time and subplot were separated. Codes for the communities (black) are as follows: the first letter (P, G, or M) indicates the treatment (perlite, granite, or mixture, respectively); the number in the middle (1 or 2) indicates the sampling date (after 8 or 20 months, respectively); and the third letter (a-j) indicates the subplot. For example, M2d indicates the collembolan community for treatment $\mathrm{M}$ in subplot d, sampled 20 months after the experimental soil boxes were established. Arrows represent the factors (abundance of microarthropods, fine-root biomass, accumulated organic matter, water content, subplot, and elapsed time). The 15 dominant collembolan taxa (each accounting for $>1 \%$ of the total number of individuals on at least one sampling date) are shown in red. Abbreviations used for the collembolan taxa are as follows: Arpl, Arrhopalites sp.; Dsri, Desoria sp.3; Etmb, Entomobrya sp.; Flsm, Folsomia octoculata; Frsj, Friesea japonica; Istm, Isotoma carpenteri; Lpdc, Lepidocyrtus sp.; Lpgt, Lophognathella choreutes; Mglt, Megalothorax minimus; Ocpd, Oncopodura yosiiana; Onyf, Onychiurus flavescens; Smth, Sminthurinus sp.; Snld, Sinella dubiosa; Tmcr, Tomocerus spp.; Ttrc, Tetracanthella sylvatica. 


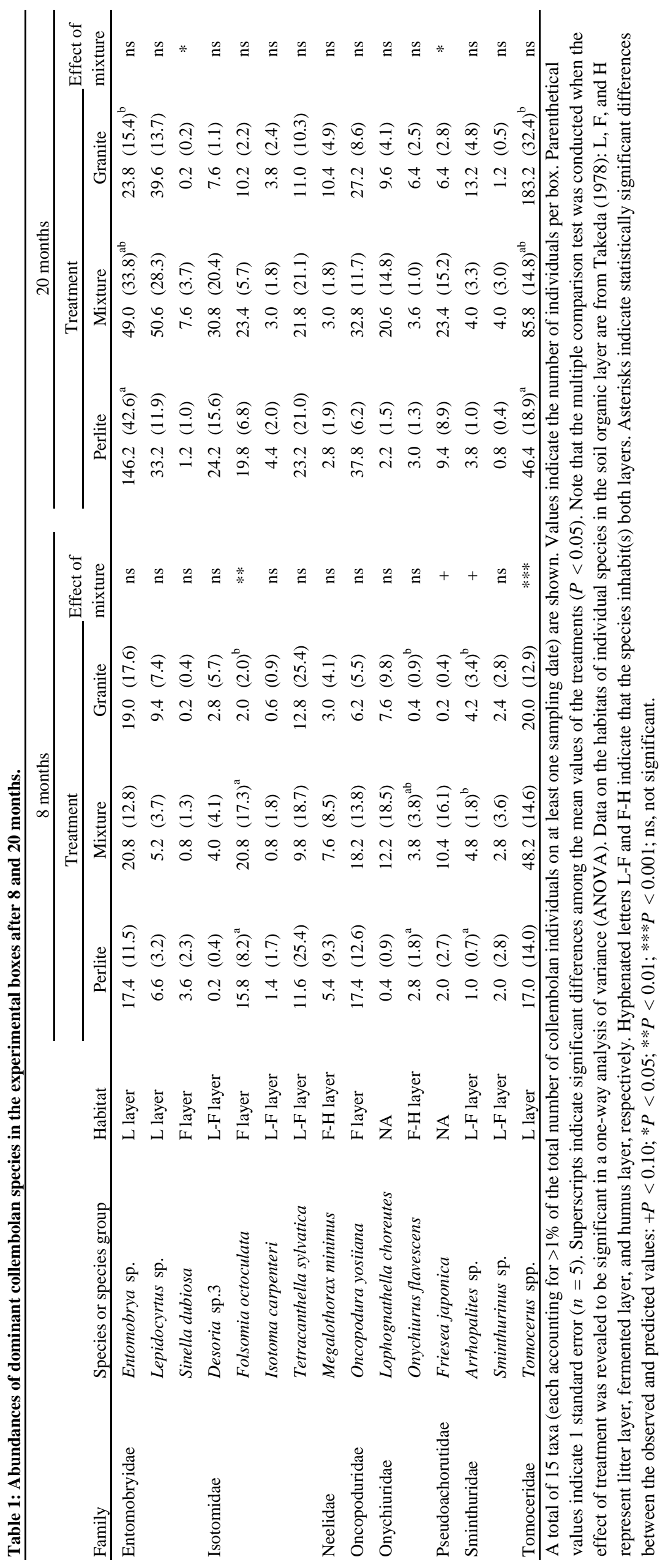

